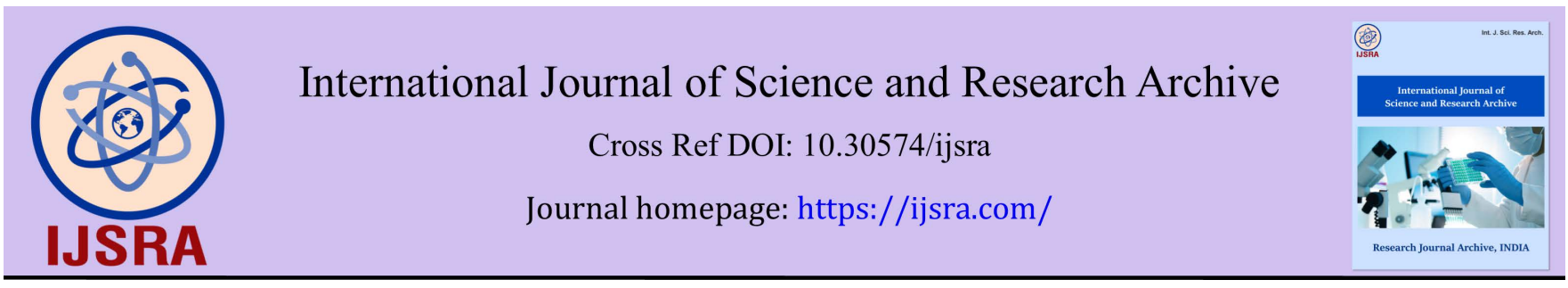

(RESEARCH ARTICLE)

\title{
Factors determining family planning services usage among women of reproductive age
}

\author{
Jane N. Mugwe $1,{ }^{*}$, and Patricia Wangari 2 \\ ${ }^{1}$ Biological and Biomedical Sciences, Laikipia University, Nyahururu, Kenya \\ ${ }^{2}$ Maternity department, Bondeni maternity, Nakuru, Kenya
}

International Journal of Science and Research Archive, 2021, 02(01), 055-059

Publication history: Received on 29 January 2021; revised on 06 Februay 2021; accepted on 08 Februay 2021

Article DOI: https://doi.org/10.30574/ijsra.2021.2.1.0018

\begin{abstract}
Family planning services allows individuals to achieve desired birth spacing and family size, and contributes to improved health outcomes for infants, children, women, and families. Family planning is one of the 10 great public health achievements of the 20th century. A number of contraceptive methods are available in family planning clinics to prevent unwanted pregnancy each with particular advantages and disadvantages. This study was conducted to determine factors influencing the uptake of contraceptives among women of reproductive age attending a maternal care health and family planning clinic. Their social demographic characteristics, family planning method used and the association between demographic factors and contraceptive methods were analyzed. There were significant positive correlations between age, education and preferred methods of contraception.
\end{abstract}

Keywords: Family Planning Services; Methods Of Contraception; Obstacles To Accessing Family Planning; Uptake Of Family Planning Services.

\section{Introduction}

The World Health Organization (WHO) describes family planning services as the ability of individuals and couples to anticipate and attain their desired number of children and the spacing and timing of their births. It is achieved through use of contraceptive methods and the treatment of involuntary infertility [2]. Family planning which has been cited as one of the 10 great public health achievements of the 20th century [3] is sometimes used as a synonym for access to and the use of contraception; however, it often involves methods and practices in addition to contraception[11].Modern methods of contraception prevent unintended pregnancies, reduce the number of abortions, and lower the incidence of death and disability related to complications of pregnancy and childbirth [21].

Family planning programs are now considered a key part of a comprehensive development strategy and the commitments of the program are specific to each country; the United Nations Sustainable Development Goals reflects this international consensus [1]. The proportion of the need for family planning satisfied by modern methods, Sustainable Development Goals (SDG) indicator 3.7.1, was 75.7\% globally in 2019 [16]. Worldwide in 2019, among the 1.9 billion women of reproductive age group (15-49 years), 1.1 billion have a need for family planning; of these, 842 million are using contraceptive methods, and 270 million have an unmet need for contraception [16];[22].

A recommendation by the US Centers for Disease Control (CDC) encourages men and women to formulate a reproductive life plan, to help them in avoiding unintended pregnancies and to improve the health of women and reduce adverse pregnancy outcomes[4].Raising a child requires significant amounts of resources: time [5],social, financial [12], and environmental [13]. Planning can help assure that resources are available. The purpose of family planning is

${ }^{*}$ Corresponding author: Jane N. Mugwe

Biological and Biomedical Sciences, Laikipia University, Nyahururu, Kenya.

Copyright (C) 2021 Author(s) retain the copyright of this article. This article is published under the terms of the Creative Commons Attribution Liscense 4.0. 
to make sure that any couple, man, or woman who has a child has the resources that are needed [6].Both early and late motherhood have increased risks. Young teenagers face a higher risk of complications and death as a result of pregnancy [22].Waiting until the mother is at least 18 years old before trying to have children improves maternal and child health [7]. Also, if additional children are desired after a child is born it is healthier for the mother to wait at least 2 years after the previous birth before attempting to conceive (but not more than 5 years [7].

\subsection{Methods of contraception}

A number of contraceptive methods are available to prevent unwanted pregnancy.Methods of contraception include oral contraceptive pills, implants, injectables, patches, vaginal rings, Intra uterine devices, condoms, male and female sterilization, lactational amenorrhea methods, withdrawal and fertility awareness based methods. These methods have different mechanisms of action and effectiveness in preventing unintended pregnancy. Effectiveness of methods is measured by the number of pregnancies per 100 women using the method per year. Methods are classified by their effectiveness as commonly used into: very effective (0-0.9 pregnancies per 100 women); effective (1-9 pregnancies per 100 women); moderately effective (10-19 pregnancies per 100 women); less effective (20 or more pregnancies per 100 women; [22]. Only one contraceptive method, condoms, can prevent both a pregnancy and the transmission of sexually transmitted infections, including HIV [22].

Ensuring access for all people to their preferred contraceptive methods advances several human rights including the right to life and liberty, freedom of opinion and expression and the right to work and education, as well as bringing significant health and other benefits. Use of contraception prevents pregnancy-related health risks for women, especially for adolescent girls, and when births are separated by less than two years, the infant mortality rate is $45 \%$ higher than it is when births are 2-3 years and 60\% higher than it is when births are four or more years apart [16]. It offers a range of potential non-health benefits that encompass expanded education opportunities and empowerment for women, and sustainable population growth and economic development for countries.

\subsection{Obstacles to accessing family planning}

There are many reasons as to why women do not use contraceptives. These reasons include logistical problems, scientific and religious concerns, and limited access to transportation in order to access health clinics, lack of education and knowledge and opposition by partners, families or communities plus the fact that no one is able to control their fertility beyond basic behavior involving conception. The United Nations Population Fund (UNFPA) says that efforts to increase access must be sensitive to cultural and national contexts, and must also consider economic, geographic and age disparities within countries [21].

According to UNFPA, poorer women and those in rural areas are said to often have less access to family planning services. This can lead to higher rates of unintended pregnancy, increased risk of HIV and other STIs, limited choice of contraceptive methods, and higher levels of unmet need for family planning [21]. For national, international, or local health programs involved in family planning, the use of standard indicators [9] is encouraged, to track barriers to effective family planning along with the efficacy, uptake, and provision of family planning services [8].

The world's largest international source of funding for population and reproductive health programs is the United Nations Population Fund (UNFPA). The World Health Organization (WHO) and World Bank estimate that \$3 per person per year would provide basic family planning, maternal and neonatal health care to women in developing countries. This would include contraception, prenatal, delivery, and post-natal care in addition to postpartum family planning and the promotion of condoms to prevent sexually transmitted infections[18].

\subsection{Uptake of family planning services}

Despite the huge benefits of family planning services, their uptake still remains low. 214 million women of reproductive age in developing countries who do not want to become pregnant are not using a modern contraceptive method [23]. This could be a result of a limited choice of methods, limited access to contraception, fear of side-effects, cultural or religious opposition, poor quality of available services, user or provider bias, or gender-based barriers. In Africa, $24.2 \%$ of women of reproductive age do not have access to modern contraction. Meeting the unmet need for contraception could prevent 104,000 maternal deaths per year, a 29\% reduction of women dying from postpartum hemorrhage or unsafe abortions.[19].

According to the UN Department of Economic and Social Affairs: Population Division, 64\% of the world uses contraceptives while $12 \%$ of the world population's need for contraceptives is unmet. In the least developed countries, $22 \%$ of the population does not have access to contraceptives, and $40 \%$ use contraceptives [14].This study aimed at 
determining factors influencing the uptake of contraceptives among women of reproductive age attending a maternal care health and family planning clinic.

\section{Methodology}

A descriptive cross sectional study design was used to sample women of reproductive age of 20-49 years attending the clinic. Data was collected using close- and open-ended questionnaires through which a total of 80 individuals responded.

\section{Results}

The social demographic characteristics showed that most of the participants were aged between 26-31 (24, 30\%) while the majority had secondary level of education $(36,45 \%)$. A total of $36(45 \%)$ of respondents were married and most of them $(34,42.5 \%)$ were housewives.

Most of the respondents (90\%) had prior knowledge of family planning methods and they also knew of several methods that are available in the market. During the study period, $47.5 \%$ (38) of respondents preferred implants while $5 \%$ (4) preferred intra uterine device (IUD) as their choice of contraceptive method., 35\% (28) of respondents preferred injectable and $7.5 \%$ (6) preferred oral contraceptives (Figure 1). 5\% of respondents preferred other methods that included condom use.

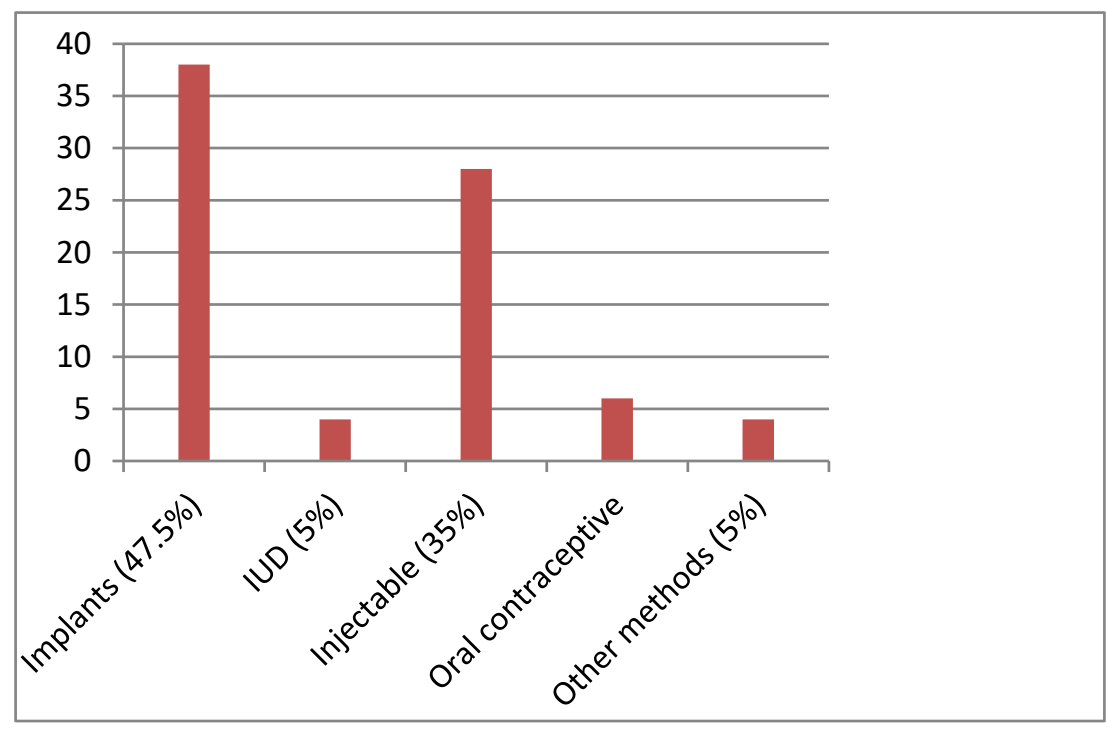

Figure 1Preferred methods of contraception

\subsection{Association between demographic factors and contraceptive methods}

Significant correlations were observed between age and education with the preferred methods of contraceptives. For example, there was significant correlation between the age brackets $32-37$, $(r=0.393 p<0.05)$ and preferred method of contraceptive (injectable) and between the age brackets $38-43(\mathrm{r}=0.330, \mathrm{p}<0.05)$ and their preferred method of contraceptives (implants). There was significant association between the level of education and methods of contraceptives. For instance, a significant correlation was observed between secondary level recipients ( $\mathrm{r}=0.392$, $\mathrm{p}<0.05$ ) and the implants, while the association between tertiary level of education recipients and intra uterine device use was significant $(\mathrm{r}=0.325 \mathrm{p}<0.05)$.

The study found that $80 \%$ of the respondents accessed contraceptives from the clinic while the rest obtained from local pharmacies or other private clinics. However, $17.5 \%$ of the participants reported that their preferred method of contraceptives were unavailable and so they had to settle for an alternative method while $27.5 \%$ of participants cited distance to the clinic as being a barrier to accessing family planning services. 


\section{Conclusion}

There are several determinants of family planning service usage within the communities. Middle aged women of higher levels of education preferred the long-acting reversible contraception methods such as the implants or intra uterine devices. Women with lower education levels and income are less likely to seek family planning services. Among the barriers to women use of family planning services include: unavailability to the contraceptive method of choice, family planning clinic locations, limited access to publicly funded services and the cost of the services.

\section{Compliance with ethical standards}

\section{Acknowledgments}

The authors would like to thank the management of Bondeni Maternity for all the assistance and cooperation.

\section{Disclosure of conflict of interest}

The authors declare no conflict of interests.

\section{Statement of informed consent}

Informed consent was obtained from all individual participants included in the study.

\section{References}

[1] Bongaarts, John. The Impact of Family Planning Programs on Unmet Need and Demand for Contraception. Studies in Family Planning, 2014; 45 (2):247-62.

[2] Butler, Adrienne Stith and Clayton, Ellen Wright 2009. Program, Institute of Medicine (US) Committee on a Comprehensive Review of the HHS Office of Family Planning Title X. Overview of Family Planning in the United States. National Academies Press (US).

[3] Centers for Disease Control and Prevention. Achievements in public health,: Family planning. MMWR Weekly. 1900-1999; 48 (47):1073-80.

[4] Centers for Disease Control and Prevention. 2006. "Recommendations to improve preconception health and health care - United States: A report of the CDC/ATSDR Preconception Care Work Group and the select panel on Preconception Care"

[5] Center for Nutrition Policy and Promotion (CNPP). "Expenditures on Children by Families, 2007; Miscellaneous Publication Number 1528-2007". United States Department of Agriculture. Archived from the original on 2008; 03:08.

[6] CDPH, 2012"Office of Family Planning". California Department of Public Health. Archived from the original on 2012; 03:08.

[7] Healthy Timing and Spacing of Pregnancy: HTSP Messages". USAID. Retrieved 2008-05-13. "Family planning/Contraception". World Health Organization. Retrieved 2018; 03:06.

[8] www.cdc.gov.

[9] www.measureevaluation.org.

[10] Lu, Yao and Slusky, David J G. The Impact of Women's Health Clinic Closures on Fertility". American Journal of Health Economics, 2018; 5 (3): 334-359.

[11] Packham, Analisa. Family planning funding cuts and teen childbearing".Journal of Health Economics, 2017; 55:168-185.

[12] https://www.msmoney.com/mm/planning/marriage/family_planning .htm.

[13] Wynes, S and Nicholas, K A. "The climate mitigation gap: Education and government recommendations miss the most effective individual actions". Environmental Research Letters. 2017; 12 (7):074024.

[14] United Nations, Department of Economic and Social Affairs, Population Division 2014. Abortion Policies and Reproductive Health around the World (Report). United Nations. 
[15] Karen Hardee. (Population Council), David Wofford (Meridien Group International), NanditaThatte (World Health Organization), "Family Planning Evidence Briefs" prepared for the Family Planning Summit held in London on July 11, 2017.

[16] Kantorová V, Wheldon MC, Ueffing P, Dasgupta ANZ. Estimating progress towards meeting women's contraceptive needs in 185 countries: A Bayesian hierarchical modelling study.

[17] United Nations, Department of Economic and Social Affairs, Population Division. Family Planning and the 2030 Agenda for Sustainable Development. New York: United Nations.

[18] http://www.globalhealth.org/news/article/2319)

[19] www.apha.org.

[20] www.prb.org

[21] www.unfpa.org.

[22] World Health Organization (WHO; 2020). Family planning/contraception methods

[23] https://www.who.int/mediacentre/factsheets/fs351. 